\title{
Demographic and Clinical Manifestations of the Patients with Parkinson's Disease in Cienfuegos City
}

\author{
Julio López Argüelles ${ }^{1 *}$, Leydi M Sosa Aguila², Aleima B Rodríguez Carvajal' ${ }^{1}$, Georgina \\ González Alba ${ }^{1}$, Lisan Montalvo Manso ${ }^{1}$, Didiesdle Herrera Alonso ${ }^{1}$ and Sandra Mendez \\ Rodriguez ${ }^{3}$ \\ ${ }^{1}$ Neurology service, Cienfuegos, Cuba \\ ${ }^{2}$ Genetic Center, Cienfuegos, Cuba
}

${ }^{3}$ Neurorehabilitation service, Cienfuegos, Cuba

*Corresponding author: Julio López Argüelles, Neurology service, Cienfuegos, Cuba

\section{ARTICLE INFO}

Received: 慧 August 24, 2019

Published: 栔 August 29, 2019

Citation: Julio López A, Leydi M Sosa A, Aleima B Rodríguez C, Georgina González A, Lisan Montalvo M, et al., Demographic and Clinical Manifestations of the Patients with Parkinson's Disease in Cienfuegos City. Biomed J Sci \& Tech Res 21(1)-2019. BJSTR. MS.ID.003537.

Keywords: Degenerative Disease; Parkinson's Disease; UPDRS; Rigidity; Tremor, Hoehn and Yahr scale

\begin{abstract}
Parkinson's disease (PD) described for the first time in 1817 by James Parkinson, is kept as the second degenerative disorder of the central nervous system. The etiology and the pathogenic mechanisms of the PD are, and possibly will continue to be it during many years, strangers. This paper is the first of its type in our environment where we plan to determine the demographic and clinical manifestations of the patients with PD looked after in our center. We studied 118 patients with diagnosis of idiopathic PD attended on specialized consultation, since June 2010 to the same month of 2011, to those which it was carried to them out survey with demographic, clinical data studies included UPDRS, Hoehn and Yahr scales. Results: the greatest number of patients there contributed it Cienfuegos (49\%), there was greater frequency of the male sex on the feminine (71:47), the mean age of beginning was of $62 \pm 9.9$, and the mean evolution of 68 months, the greatest number of the UPDRS motor and the Hoehn and Yahr scale showed it the age group from 56 to 64 years. There existed predominance in the rural areas (81:37) and well water (71:47), in addition to of the white race (101:17), 18.8\% of patients had family history of PD.
\end{abstract}

\section{Introduction}

Parkinson's disease (PD), described for the first time in 1817 by James Parkinson in its monograph of 66 pages An Essay on the shaking palsy, where he points it out as a condition consisting of "involuntary shaking movements, with reduction of the muscular potency in the passive and active mobility. PD remains as the second degenerative disorder of the central nervous system [1,2]. The etiology and the pathogenic mechanisms of PD are, and possibly will continue to be it during many years, strangers [3]. Has been suggested that the cause of the PD would be multifactorial and would intervene genetic factors, environmental and aging [4,5]. Within its etiology or risk factors deserves special interest the age, then this is directly proportional to degenerative processes, the mean age at beginning is 60 years old, and the incidence increases significantly with the age $[3,6]$; the forms of early onset of the disease are usually inherited, ther investigators believe that the disease is result of a combination of genetic susceptibility and exposure to one or more environmental factors that trigger the disease $[7,8]$.

PD affects around 50 percent more to men than women, but the reasons of this discrepancy are not clear [9-11]. Although appears in people throughout the world, a number of studies has found a greater incidence in the developed countries, possibly due to the largest exposure to pesticides or toxins in those countries. Other studies have found a risk increased in people who live in rural areas and in those that work in certain professions, although the studies to date are not conclusive and are not clear the reasons of the apparent risks [12-18]. The joint analysis of 5 European Communities did not identify any substantial difference in the prevalence of the PD in the European countries. The general prevalence was 1.6 per 100 populations, and a substantial proportion of the patients with PD clinical specific never had sought medical care. The variable incidence rates in different cultures at least are partly related to the 
lack of uniform criteria for diagnosis. With the present article we intended to characterize patients with PD in our province.

\section{Methods}

A descriptive study was conducted, to the patients with PD who went to the consultation of this disease of the University Hospital Dr. Gustavo Aldereguía Lima in Cienfuegos city, since the month of June 2010 until the same month of the following year. For the same include all the patients with diagnosis of Idiopatic Parkinson disease [4], in total 118 patients who fulfilled the following criteria: Patients with diagnosis of PD, excluding: Atypical or secondary Parkinsonism. In order to fulfill the research purpose a list or survey was created for the collection of the data, of easy and fast application that included: demographic data (age, onset age, sex, race, origin, schooling), scale scoring: UPDRS, Hoenh and Yahr scales, clinical manifestations at the beginning and in evolutionary stages of the disease. The sample was analyzing according age groups.

Table 1: Clinics characteristics according to age groups.

\section{Results}

As a result of the present work we have to with regard to the variables related to the beginning of the disease (Table 1); the onset age was superior in the group of patient over 65 years old (68.4 $\pm 7.3, \mathrm{p}<0,0001)$, superior even to the mean of the taken sample $(64,2 \pm 9,9)$, exists a clear predominance of the male sex (71:47), being the general evolution time of 68 months without a significant variation between groups. The UPDRS scale showed a mean of $19,1 \pm 10,7$ without significance between groups $(p=0,08)$ being the majority between a second and third stage of the Hoenh and Yahr scale. In almost all the patients the school level did not go from primary (Table 2), with clear predominance of people who live in rural areas (81:37), although the majority of the patients belong to the provincial head. An unequal distribution appears with regard to the race with white predominance (101:17), in addition to of the patients who take well water on those which do it of the water supply system with a relation of 71:47.

\begin{tabular}{|c|c|c|c|c|c|c|}
\hline & Total n=118 & $\mathbf{4 5}$ & $\mathbf{4 6 - 5 5}$ & $\mathbf{5 6 - 6 4}$ & $\mathbf{2 5 5}$ & $\mathbf{p}$ \\
\hline Female: Male & $47: 71$ & $2: 1$ & $1: 05$ & $6: 15$ & $38: 50$ & \\
\hline Onset mean age & $64,2 \pm 9,9$ & $39,0 \pm 1,1$ & $47,8 \pm 2,4$ & $55,23 \pm 5,3$ & $68,4 \pm 7,3$ & $<0,001$ \\
\hline Evolution Time a & $68,0 \pm 5,1$ & $50,0 \pm 1,1$ & $52,4 \pm 28,8$ & $46,9 \pm 49,4$ & $74,9 \pm 52,2$ & 0,08 \\
\hline UPDRSm & $19,1 \pm 10,7$ & $14,2 \pm 7,8$ & $17,3 \pm 8,7$ & $19,6 \pm 10,5$ & $19,2 \pm 11,3$ & 0,85 \\
\hline $\begin{array}{c}\text { Hoenh and Yahr } \\
\text { Scale }\end{array}$ & $3,0 \pm 1,4$ & $2,0 \pm 1,0$ & $2,0 \pm 1,0$ & $3,0 \pm 0,5$ & $2,0 \pm 0,7$ & 0,9 \\
\hline \multicolumn{5}{|c|}{ a: Duration in months } \\
\hline
\end{tabular}

Table 2: Demographic characteristics according to age groups.

\begin{tabular}{|c|c|c|c|c|c|}
\hline & Total $n=118$ & $\leq 45$ & $46-55$ & $56-64$ & $\geq 65$ \\
\hline Schooling & Primary & Primary & Primary & Secundary & Primary \\
\hline Origin & \multirow{2}{*}{$81: 37$} & \multirow{2}{*}{$3: 1$} & \multirow{2}{*}{$3: 3$} & \multirow{2}{*}{$17: 04$} & \multirow{2}{*}{$58: 29$} \\
\hline (Rural:Urban) & & & & & \\
\hline Race & \multirow{2}{*}{ 101:17 } & \multirow{2}{*}{$4: 0$} & \multirow{2}{*}{$5: 1$} & \multirow{2}{*}{$18: 3$} & \multirow{2}{*}{$74: 13$} \\
\hline (white: Black) & & & & & \\
\hline Origin of the Water(Well:Water Supply System) & $71: 47$ & $3: 1$ & $4: 2$ & $16: 5$ & 48:39 \\
\hline Family History of PD & $22(18,8 \%)$ & 1 & 2 & 6 & 13 \\
\hline \multicolumn{6}{|c|}{ PD: Parkinson's disease } \\
\hline
\end{tabular}

It becomes evident in the study sample that $18.8 \%$ of the patients had preceding family history of PD. In Tables 2 and 3 we see the onset form predominance in the right upper limb, although a sizable number of patients made them symmetrically. The greatest percentage of the patients had both at the beginning

Table 3: Beginning place according to age groups.

\begin{tabular}{|c|c|c|c|c|c|}
\hline & Total $n=118$ & $\leq 45(\%)$ & 46 a 55 (\%) & 56 a $64(\%)$ & $\geq 65(\%)$ \\
\hline Right arm & 56,3 & 0 & 4,2 & 14,1 & 38,0 \\
\hline Left arm & 40,6 & 0 & 2,9 & 4,3 & 33,3 \\
\hline Right leg & 15,9 & 0 & 1,4 & 5,8 & 8,7 \\
\hline Left leg. & 10,4 & 1,5 & 0 & 1,5 & 7,5 \\
\hline Symmetric & 16,2 & 0 & 0 & 4,4 & 11,8 \\
\hline
\end{tabular}

and in their evolution a predominance of tremor form, basically the young people. The majority of the patients had an onset form bit a beginning as in the current state of the disease of the tremor form on the rigid-akinetic without significant difference among the studied age groups (Table 4). 
Table 4: Forms of presentation according to age groups.

\begin{tabular}{|c|c|c|c|c|c|c|c|}
\hline & & Total $n=118$ & $\leq 45(\%)$ & $46-55(\%)$ & $56-64(\%)$ & $\geq 65(\%)$ & p (\%) \\
\hline \multirow{2}{*}{ Onset } & Tremor & 69,6 & 100 & 40 & 69,2 & 70,0 & 0,9 \\
\hline & Rigid-Akinetic & 30,4 & 0 & 60 & 30,8 & 30,0 & 0,6 \\
\hline \multirow{2}{*}{ Current stage } & Temblor & 56,5 & 100 & 100 & 50 & 55,6 & 0,6 \\
\hline & Rigid-Akinetic & 43,5 & 0 & 0 & 50 & 44,4 & \\
\hline \multicolumn{8}{|c|}{ Data taken from conducted survey } \\
\hline
\end{tabular}

\section{Discussion}

In our Province of Cienfuegos, small Southerner locality of Cuba with a population of no more than 450000 inhabitants, have observed a striking increase of the incidence of patients with PD in the consultation specialized for this disease, finding as characteristic that is significant the predominance of the male sex and although some authors have reported this predominance [19], in our sample the relation is almost of $2: 1$, the onset mean was in the sixth decade, same result that in others latitudes $[7,20,21]$. A striking datum is that, despite the fact that the average of the time of evolution was only of 68 months, the values of the motor UPDRS and of the Stage of Hoenh and Yahr was significant with an average of 19.13 and 3 points respectively. The demographic factors related to these patients were shown among the average ranges proposed by the literature, as the schooling, a predominance in the rural areas, specifically those which have as principal water supply that of well, rich in electrolytes.

Having in addition: the race (predominance of white race) and family history of PD with 18\%, contrasts with other authors who show lower values, except in certain localities [22-24]. The beginning predominates widely by the right arm what could be with regard to the predominance of the diestrums in the sample perhaps by the increase of the motor activity of that limb, with an anatomic and functional representation, although 16\% had a symmetrical beginning. Carrying out the analysis with regard to the onset form prevails the tremor form although the percentages are being equalized to the rigid-akinetic form as there establishes it the own natural history of disease without significant significance between groups.

\section{References}

1. Parkinson J (2002) An Essay on the Shaking Palsy 1817. Shrwood, Neely and Jones, J Neuropsychiatry Clin Neurosci 14: 2

2. López Argüelles J, Sosa Aguila LM, Rodriguez Carbajal AB, Montalvo Manso L (2019) Progress in knowledge of Alzheimer's disease. Archives in Neurology \& Neuroscience 4(3).

3. López Argüelles J, Rodriguez Carbajal A, Gonzalez Alba G, Sosa Aguila LM, Montalvo Manso L (2019) Factors Related with Frontal Dysfunction in Early Stages of Parkinson Disease. J Alzheimers Neurodegener Dis 5018.

4. Capriotti T, Terzakis K (2016) Parkinson Disease. Home Healthcare Now 34(6): 300-307.

5. Zhou MZ, Gan J, Wei YR, Ren XY, Chen W, et al. (2013) The association between non-motor symptoms in Parkinson's disease and age at onset. Clin Neurol Neurosurg 115(10): 2103-2107.
6. López Argúelles J, Sosa Aguila LM, Rodriguez Carbajal AB, Georgina Gonzalez Alba, Lisan Montalvo Manso (2018) Blepharospasm followed by Parkinson's disease in two brothers case presentation in a family. Int J Fam Commun Med 2(4): 245-246.

7. Alcalay RN, Dinur T, Quinn T, Sakanaka K, Levy O, et al. (2014) Comparison of Parkinson Risk in Ashkenazi Jewish Patients with Gaucher Disease and GBA Heterozygotes. JAMA Neurol 71(6): 752-757.

8. Sun Y, Chang YH, Chen HF, Su YH, Su HF, et al. (2012) Risk of Parkinson disease onset in patients with diabetes: a 9-year population-based cohort study with age and sex stratifications. Diabetes Care 35(5): 10471049 .

9. Ascherio A, Zhang SM, Hernan MA, Kawachi I, Colditz GA, et al. (2001) Prospective study of caffeine consumption and risk of Parkinson's disease in men and women. Ann Neurol 50(1): 56-63.

10. Domingo A, Lee LV, Bruggemann N, Freimann K, Kaiser FJ, et al. (2014) Woman With X-Linked Recessive Dystonia-Parkinsonism: Clue to the Epidemiology of Parkinsonism in Filipino Women? JAMA Neurol 71(9): 1177-1180.

11. Rocca WA, Bower JH, Maraganore DM, Ahlskog JE, Grossardt BR, et al. (2008) Increased risk of parkinsonism in women who underwent oophorectomy before menopause. Neurology 70(3): 200-209.

12. López Argüelles J, Borroto LA, Sosa Aguila LM, Rodriguez Carbajal AB (2019) Prevalence of Parkinson's disease in an urban area of Cienfuegos city. Int J Fam Commun Med 3(1): 12-14.

13. Giroud JL, Esteban EM, Collado F (1998) Prevalencia de la enfermedad de Parkinson en un área urbana de la provincia de Cuidad de la Habana,Cuba. Estudio poblacional puerta a puerta. Rev Neurol 13: 3339.

14. Osaki Y, Morita Y, Kuwahara T, Miyano I, Doi Y (2010) Prevalence of Parkinson's disease and atypical parkinsonian syndromes in a rural Japanese district. Acta Neurol Scand 124(3): 182-187.

15. Wermuth L, Bech S, Petersen MS, Joensen P, Weihe P, et al. (2008) Prevalence and incidence of Parkinson's disease in The Faroe Islands. Acta Neurol Scand 118(2): 126-131.

16. Basolo Osinaga E, Abecia Inc, Fernandez Diaz E, Barcenilla Laguna A, Banares Onraita T (2006) The prevalence and pharmacological cost of Parkinson's disease in Spain. Rev Neurol 43(11): 641-645.

17. Totaro R, Marini C, Pistoia F, Sacco S, Russo T, et al. (2005) Prevalence of Parkinson's disease in the L'Aquila district, central Italy. Acta Neurol Scand 112(1): 24-28.

18. Claveria LE, Duarte J, Sevillano MD, Perez Sempere A, Cabezas C, et al. (2002) Prevalence of Parkinson's disease in Cantalejo, Spain: a door-todoor survey. Mov Disord 17(2): 242-249.

19. Abboud H, Reyes D, Genc G, Ahmed A, Gostkowski M, et al. (2019) Height and weight changes after deep brain stimulation in patients with Parkinson disease: role of clinical subtypes. Heliyon 5(6): e01862.

20. Butcher NJ, Kiehl TR, Hazrati LN, Chow EW, Rogaeva E, et al. (2013) Association between early-onset Parkinson disease and 22q11.2 deletion syndrome: identification of a novel genetic form of Parkinson disease and its clinical implications. JAMA Neurol 70(11): 1359-1366.

21. Oaks AW, Frankfurt M, Finkelstein DI, Sidhu A (2013) Age-Dependent Effects of A53T Alpha-Synuclein on Behavior and Dopaminergic Function. PLoS One 8(4): e60378. 
22. Tang H, Huang J, Nie K, Gan R, Wang L, et al. (2016) Cognitive profile of Parkinson's disease patients: a comparative study between early-onset and late-onset Parkinson's disease. Int J Neurosci 126(3): 227-234.

23. Vanderheyden JE, Gonce M, Bourgeois P, Cras P, De Nayer AR, et al. (2010) Epidemiology of major depression in Belgian parkinsonian patients. Acta Neurol Belg 110(2): 148-156.

\section{ISSN: 2574-1241}

DOI: 10.26717/BJSTR.2019.21.003537

Julio López Argüelles. Biomed J Sci \& Tech Res

(C)

Submission Link: https://biomedres.us/submit-manuscript.php
24. Savci C, Sendir M (2009) Evaluation of health related quality of life in patients with Parkinsons disease. Neurosciences (Riyadh ) 14(1): 60-66.

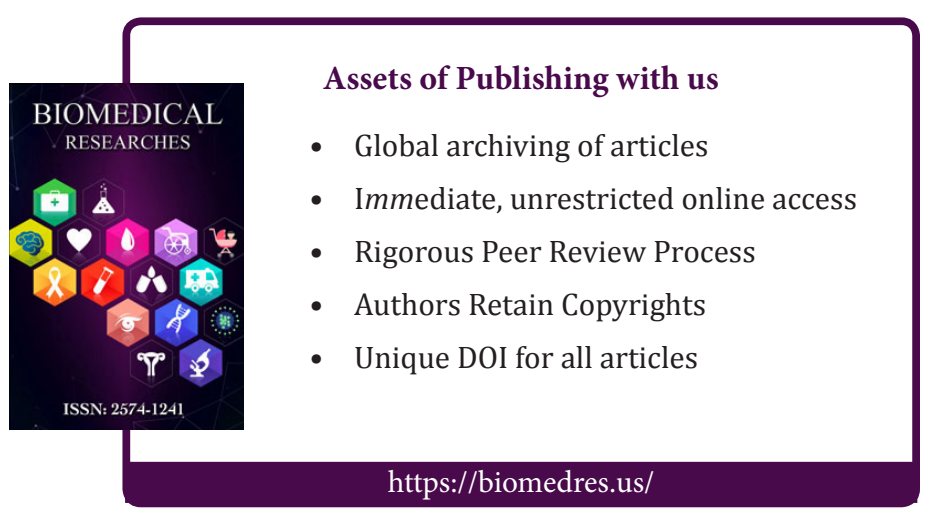

